\title{
Basic sanitation, socioeconomic conditions, and degree of risk for the presence and maintenance of malaria in a low-transmission area in the Brazilian Amazon
}

\author{
Thais Hetierre Abreu Monteiro[1], Tânia do Socorro Souza Chaves ${ }^{[2]}$, \\ Haroldo José de Matos ${ }^{[2]}$, Nelson Fernando de Lisboa Sofffiatti ${ }^{[2]}$, \\ Ricardo José de Paula Souza e Guimarães ${ }^{[2]}$, Luis Henrique Rocha Guimarães ${ }^{[2]}$, \\ Ana Maria Revoredo Ventura ${ }^{[2]}$ and Ricardo Luiz Dantas Machado[1],[2]
}

[1]. Programa de Pós-Graduação em Biologia dos Agentes Infecciosos e Parasitários, Universidade Federal do Pará, Belém, Pará, Brazil. [2]. Instituto Evandro Chagas, Secretaria de Vigilância Sanitária, Ministério da Saúde, Ananindeua, Pará, Brazil.

\begin{abstract}
Introduction: This study aimed to evaluate basic sanitation and socioeconomic indicators, reported cases of malaria, and risk of contracting malaria in the Ananindeua municipality, State of Pará. Methods: Data on basic sanitation and socioeconomic dimensions were taken from the Brazilian Institute of Geography and Statistics [Instituto Brasileiro de Geografia e Estatística (IBGE)] 2010 census. Epidemiological malaria information was taken from the Epidemiological Malaria Surveillance Information System [Sistema de Informação de Vigilância Epidemiológica de Malária (SIVEP/Malaria)], between 2003 and 2013 of the Ministry of Health and from the SIVEP/Malaria forms of the municipality's Endemic Diseases Unit for 2,013 cases. Results: Our data do not confirm the correlation among indicators of basic sanitation, socioeconomic conditions, and water supply with malaria cases. Of the 1,557 cases evaluated, most were caused by Plasmodium vivax, with rare cases of Plasmodium falciparum and mixed infections. There were 756 notifications in 2003. The number of reported cases was sharply reduced between 2006 and 2012, but a 142-case outbreak occurred in 2013. Ananindeua municipality's Annual Parasite Index indicated low risk in 2003 and no risk in other years, and the 2,013 cases were predominantly male individuals aged $\geq 40$ years. Conclusions: Our data confirm the non-endemicity of malaria in the Ananindeua municipality, as the Annual Parasite Indices described for the years 2004-2013 classify it as a risk-free area. However, the 2013 outbreak indicates the need to strengthen prevention, surveillance, and control activities to reduce the risk of new outbreaks and consequent economic and social impacts on the population.
\end{abstract}

Keywords: Malaria. Annual Parasite Index. Socioeconomic factors. Epidemiology. Brazilian Amazon.

\section{INTRODUCTION}

Brazil is a country of continental dimensions where different malaria transmission profiles are observed in three distinct environments: the Amazon and Atlantic Forest (on the coast, more frequently in the southeast region), both with a predominance of autochthonous cases, and in other areas with imported cases originating from recent trips to endemic malaria areas in Brazil or other Central and South American, African, or Asian countries ${ }^{(1)}$.

Five species of Plasmodium affect humans worldwide. In Brazil, only three species are found: Plasmodium vivax (83.7\%),

Corresponding author: Dr. Ricardo Luiz Dantas Machado. Laboratório de Malária/Instituto Evandro Chagas/SVS/MS. BR-316, Km 7 s/n, Levilândia, 67030-000 Ananindeua, Pará, Brasil.

Phone: 5591 3214-2150/2392

e-mail: ricardomachado@iec.pa.gov.br

Received 6 April 2015

Accepted 31 July 2015
Plasmodium falciparum (20\%), and Plasmodium malariae. The first species predominates in the Amazon and Atlantic Forest. Plasmodium falciparum has focal transmission in the country and is more common than P. vivax in some areas but rare or absent in others, and the rarely observed $P$. malariae is found primarily in the Atlantic Forest, along with $P$. vivax and nonhuman primate parasites ${ }^{(1)(2)(3)}$.

The Brazilian Amazon region is composed of nine States: Acre, Amapá, Amazonas, Pará, Rondônia, Roraima, Tocantins, Mato Grosso, and Maranhão. Due to the region's climate and the presence of forests that promote the maintenance of breeding sites and hence the proliferation of vectors, $99.7 \%$ of malaria cases are concentrated here ${ }^{(1)}$. However, in 2011, 98\% of events were identified in six States: Pará, Amazonas, Rondônia, Acre, Amapá, and Roraima ${ }^{(4)}$.

Of the nine Amazon States, Pará ranks first in malaria notifications. This factor is facilitated by the progressive increase in malaria records between 2010 and $2011^{(5)}$, with 25,401 positive cases reported in $2013^{(6)}$. Recently, Lima Jr et al. ${ }^{(7)}$ investigated the association between quality of life and risk of 
contracting malaria in the different municipalities of Pará from 2003-2011. They found that the Annual Parasite Indices (APIs) in $47(32.9 \%)$ of the 143 municipalities in 2011 were medium to high risk, and the mesoregion of Southwest Pará was most affected, with half of its municipalities classified as high risk and $86 \%$ of reported cases caused by $P$. vivax. In the Quality of Life Index (QLI) classification, 69.2\% of municipalities were classified as fair or poor. A moderate to high risk of contracting malaria was observed in municipalities with low QLI, with probabilities of $81 \%$ and $95.1 \%$, respectively, while those with good QLI had the lowest rates of malaria (probability of $79.2 \%$ ). The authors found that malaria in Pará is endemic in poor areas and that the disease distribution is directly related to the socioeconomic conditions of the population ${ }^{(7)}$.

Malaria outbreaks usually occur in non-endemic areas or locations, especially outside of the Amazon region. Such outbreaks are usually caused by imported cases in regions where the vector is present and can thus favor the emergence of autochthonous cases of malaria. Autochthonous cases caused by P. falciparum and $P$. vivax were diagnosed in an area in State of Minas Gerais. The vector infection source was miners carrying the parasite originating from states with malaria transmission ${ }^{(8)}$. The inexperience of healthcare professionals in the early detection of malaria cases can also contribute to outbreaks. In the absence of immediate treatment in areas where Anopheles is present, even a single malaria case can result in introduced cases, causing outbreaks ${ }^{(1)}$.

Studies exploring risk factors that may be directly associated with the emergence of malaria in the metropolitan region of Belém and characterizing an outbreak are scarce ${ }^{(7)}$. This study aimed to evaluate indicators of basic sanitation and socioeconomic dimensions in the Ananindeua municipality, State of Pará (in the metropolitan region of Belém, capital of the State of Pará), features of reported malaria cases, and the prevalent Plasmodium species and to classify the degree of risk of contracting malaria in the municipality based on malaria API for the years 2003-2013.

\section{METHODS}

\section{Study area}

The municipality of Ananindeua is located in the State of Pará, North and West of the municipality of Belém, South of the Guamá River, East of the municipality of Marituba, and Northwest of the Benevides municipality. It is one of the cities that form the Metropolitan Region of Belém (Ananindeua, Belém, Benevides, Marituba, Santa Bárbara do Pará, Santa Isabel, and Castanhal) and divided into 26 districts. The Ananindeua climate is humid tropical, with high temperatures of approximately $25^{\circ} \mathrm{C}$, a small temperature range, and regular rainfall of approximately $2,250-2,500 \mathrm{~mm}$, with the highest rainfall concentration between January and June. The relative humidity is approximately $85 \%{ }^{(9)}$. The municipality's population is 471,980 inhabitants, and it has an area of $185,057 \mathrm{~km}^{2}$ and population density of $2,477.56$ inhabitants $/ \mathrm{km}^{2(10)}$.

\section{Information sources and sample characteristics}

This observational and descriptive study used information on Ananindeua municipality, State of Pará from the 2010 Census, available on the Brazilian Institute of Geography and Statistics [Instituto Brasileiro de Geografia e Estatística (IBGE)] website ${ }^{(11)}$. Two dimensions were selected from the information available: basic sanitation, comprising the percentage of households with piped water, regular garbage collection, connection to the sewage network, or a bathroom, and socioeconomic, including population density, average income of household heads, and literacy among household heads.

Except for population density and the average income of household heads, indicators with values below $50 \%$ were considered poor levels, and those above or equal to $50 \%$ were considered good. To calculate population density, the population of the municipality of Ananindeua in 2010 as specified in the census was divided by the squared area of the municipality ${ }^{(11)}$.

Records of reported malaria cases in the Ananindeua municipality for the period 2003-2013 were obtained from the Epidemiological Malaria Surveillance Information System ${ }^{(6)}$. Part of the data necessary to calculate the Malaria API was obtained from the Epidemiological Malaria Summary, data source Municipality by Probable Infection Site. The malaria API was selected as the malaria indicator and defined as the total number of positive reported malaria cases in a given year, divided by the total estimated municipal population in the year and multiplied by one thousand ${ }^{(11)}$. Variations were ascertained and calculated as follows: the final number was divided by the initial number, the result was subtracted from 1 (i.e., result - 1), and the resulting figure was multiplied by $100^{(12)}$.

The API value was used as an epidemiological malaria classification criterion ${ }^{(13)}$, where values $\geq 50$ are classified as high risk, those from 49.9-10 are classified as medium risk, 9.9-1 low risk, and values $<1$ as risk-free. Data on the monthly numbers of positive malaria cases for 2003 and 2013 were collected through the Epidemiological Malaria Summary, a monthly data source for the municipality. For the description of the profile of reported malaria cases in Ananindeua municipality in $2013^{(6)}$, data were extracted from 126 forms of the Epidemiological Surveillance Information System (Sistema de Informação de Vigilância Epidemiológica de Malária - SIVEP/Malaria). Notably, there were 142 reported cases in the year 2013, but only 126 records were found; thus, 16 were missing.

\section{Data analysis}

Data analysis was performed using descriptive analysis techniques, focusing on the calculation of indicators describing the study population characteristics of the Ananindeua, State of Pará municipality. Data were previously tabulated in Excel. The data were consolidated into tables and plots to organize information specific to the study interests for analysis and to evaluate the most relevant epidemiological phenomena.

\section{Ethical considerations}

As the study data were obtained from publicly available sources, there was no need for prior submission to the Research 
Ethics Committee [Comitê de Ética e Pesquisa (CEP)] under Resolution 466/2012 of 12 December 2012 of the National Health Council ${ }^{(14)}$.

\section{RESULTS}

Indicators of basic sanitation and socioeconomic dimensions for the Ananindeua municipality, Belém Metropolitan Region, and State of Pará, in 2010.

Figure 1 summarizes the indicators of basic sanitation and socioeconomic dimensions in the municipality of Ananindeua (A), metropolitan region of Belém (B), and State of Pará (C). The metropolitan region of Belém had higher percentage values for the assessed indicators than the State of Pará. However, Belém had lower rates (\%) of literacy, households with bathrooms, and garbage collection and higher access to the general sewage network and water supply indicators compared to the Ananindeua municipality, with some similarity between conditions in Ananindeua and in the metropolitan region of Belém. Ananindeua municipality exhibited a population density of 2,477.56 inhabitants $/ \mathrm{km}^{2}$, an average income of household heads of $\mathrm{R} \$ 963,89$ and low piped water coverage.

Number of reported malaria cases in Ananindeua, State of Pará by Plasmodium species from 2003 to 2013

Of the 1,557 malaria cases reported in the Ananindeua municipality during the study period, 1,546 (99.3\%) were caused by $P$. vivax. Only eight cases were caused by $P$. falciparum between 2003 and 2010, and three mixed malaria (P. vivax + P. falciparum) cases were detected in 2003 and 2004 (Table 1).

Distribution of the number of malaria cases reported in Ananindeua, State of Pará and annual parasite index $(1,000$ inhabitants) from 2003 to 2013

Table 2 shows the historical malaria APIs in the Ananindeua municipality from 2003 to 2013, with peaks in the number of reported cases in the early years $(2003,2004$, and 2005) and at the end of the series (2013). The most significant decrease in this index was in 2004 and 2006, when the rate fell from 1.73 in 2003 to 0.55 in 2004 and from 0.61 in 2005 to 0.08 in 2006, i.e., malaria API decreased by $68.2 \%$ in 2003 and $86.7 \%$ in 2013 .

\section{Malaria cases reported by month in Ananindeua, State of Pará in 2003 and 2013}

The monthly series of reported malaria cases in 2003 shows a high percentage of reports in January, followed by a sudden drop in cases until March, remaining nearly constant from March to June, a small increase from June to August, declining again between August and October, rising again in October to a peak in November, and then declining until December. In 2013, the number of cases was almost constant from January to March; however, in March, a marked increase began, with a peak in April and decline until May, again displaying almost the same percentage as the first 3 months, with small oscillations until the month of December (Table 3).

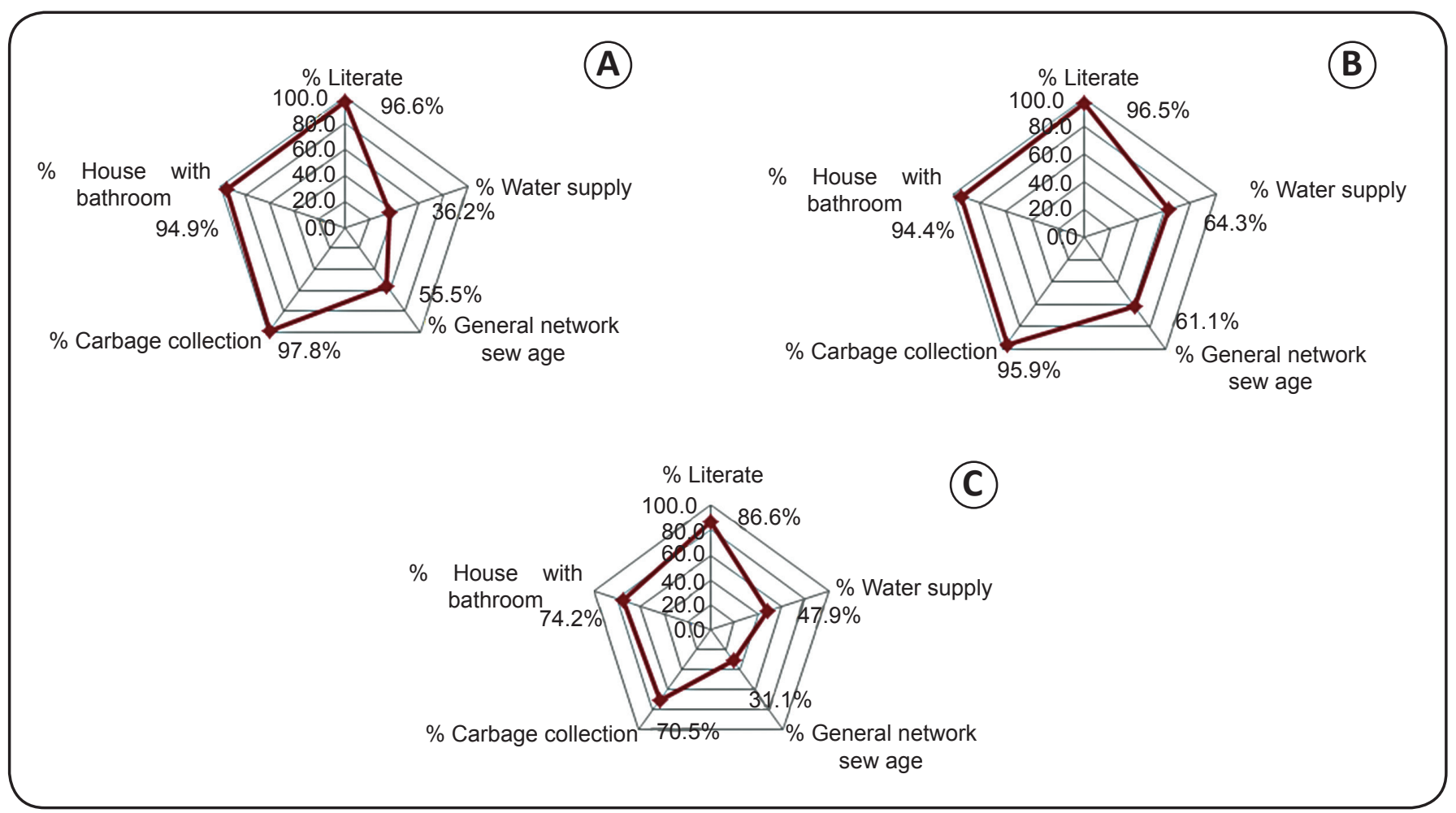

FIGURE 1 - Comparison of indicators of basic sanitation and socioeconomic conditions in the Ananindeua municipality (A), Metropolitan Region of Belém (B), and State of Pará (C) in 2010. 
TABLE 1 - Number of cases of malaria by Plasmodium species reported in Ananindeua, State of Pará, from 2003 to 2013.

\begin{tabular}{|c|c|c|c|c|c|c|c|c|c|}
\hline \multirow{3}{*}{ Year } & \multirow{3}{*}{$\begin{array}{c}\text { Positive } \\
\text { malaria cases }\end{array}$} & \multicolumn{8}{|c|}{ Plasmodium species } \\
\hline & & \multicolumn{2}{|c|}{ vivax } & \multicolumn{2}{|c|}{ falciparum } & \multicolumn{2}{|c|}{ malariae } & \multicolumn{2}{|c|}{ vivax and falciparum } \\
\hline & & $\mathrm{n}$ & $\%$ & $\mathrm{n}$ & $\%$ & $\mathrm{n}$ & $\%$ & $\mathrm{n}$ & $\%$ \\
\hline 2003 & 756 & 750 & 99.2 & 4 & 0.5 & 0 & 0.0 & 2 & 0.3 \\
\hline 2004 & 256 & 255 & 99.6 & 0 & 0.0 & 0 & 0.0 & 1 & 0.4 \\
\hline 2005 & 296 & 295 & 99.7 & 1 & 0.3 & 0 & 0.0 & 0 & 0.0 \\
\hline 2006 & 38 & 38 & 100.0 & 0 & 0.0 & 0 & 0.0 & 0 & 0.0 \\
\hline 2007 & 9 & 8 & 88.9 & 1 & 11.1 & 0 & 0.0 & 0 & 0.0 \\
\hline 2008 & 8 & 8 & 100.0 & 0 & 0.0 & 0 & 0.0 & 0 & 0.0 \\
\hline 2009 & 5 & 5 & 100.0 & 0 & 0.0 & 0 & 0.0 & 0 & 0.0 \\
\hline 2010 & 12 & 10 & 83.3 & 2 & 16.7 & 0 & 0.0 & 0 & 0.0 \\
\hline 2011 & 22 & 22 & 100.0 & 0 & 0.0 & 0 & 0.0 & 0 & 0.0 \\
\hline 2012 & 13 & 13 & 100.0 & 0 & 0.0 & 0 & 0.0 & 0 & 0.0 \\
\hline 2013 & 142 & 142 & 100.0 & 0 & 0.0 & 0 & 0.0 & 0 & 0.0 \\
\hline
\end{tabular}

Source: Sistema de Informação de Vigilância Epidemiológica de Malária (SIVEP/Malária), July/2014.

TABLE 2 - Distribution of the numbers of malaria cases reported in Ananindeua, State of Pará, and the annual parasite index (API - 1,000 inhabitants) from 2003 to 2013.

\begin{tabular}{|c|c|c|c|c|}
\hline Year & Total cases & Population* & API & Variation $(\%)^{* *}$ \\
\hline 2004 & 256 & 468,463 & 0.55 & -68.21 \\
\hline 2005 & 296 & 482,170 & 0.61 & 10.91 \\
\hline 2006 & 38 & 498,095 & 0.08 & -86.89 \\
\hline 2009 & 5 & 505,512 & 0.01 & -50.00 \\
\hline 2010 & 12 & 471,980 & 0.03 & 200.00 \\
\hline 2011 & 22 & 477,999 & 0.05 & 66.67 \\
\hline
\end{tabular}

API: annual parasite index; IBGE: Instituto Brasileiro de Geografia e Estatística.*Population estimated by IBGE. **2013 compared to 2003.

\section{Profile of malaria cases reported in Ananindeua, State of Pará in 2013}

In 2013, 142 malaria cases were recorded in the municipality. Of these, only 126 epidemiological forms were identified. Eighty-two (65.1\%) of these patients were male. Their ages ranged from 5 to 82 years, and most were $\geq 40$ years old. The most frequent education level attained was primary education $[n=58(46 \%)]$. The most frequently reported activity in the last 15 days was domestic, with 13 (10.3\%) patients, followed by agriculture and gold mining with $4(3.2 \%)$ each, mining with $3(2.4 \%)$, traveling with $2(1.6 \%)$, and plant extractivism and $\mathrm{road} / \mathrm{dam}$ construction with $1(0.8 \%)$ each. The majority of patients, i.e., 68 (54\%), declared having practiced activities other than those mentioned on the SIVEP/Malaria notification form, and no activities were marked on $30(23.8 \%)$ records (Table 4). 
TABLE 3 - Comparison of the monthly series of malaria cases reported in Ananindeua, State of Pará, from 2003 to 2013.

\begin{tabular}{|c|c|c|c|c|}
\hline Month of notification & \multicolumn{2}{|c|}{ Malaria cases 2003} & \multicolumn{2}{|c|}{ Malaria cases 2013} \\
\hline January & 273 & 30.3 & 13 & 5.7 \\
\hline March & 34 & 3.8 & 7 & 3.1 \\
\hline April & 34 & 3.8 & 99 & 43.4 \\
\hline June & 34 & 3.8 & 12 & 5.3 \\
\hline July & 47 & 5.2 & 20 & 8.8 \\
\hline August & 75 & 8.3 & 17 & 7.5 \\
\hline September & 38 & 4.2 & 7 & 3.1 \\
\hline October & 31 & 3.5 & 11 & 4.8 \\
\hline
\end{tabular}

TABLE 4 - Sociodemographic aspects of reported malaria cases by sex in Ananindeua municipality, State of Pará, 2013.

\begin{tabular}{|c|c|c|c|}
\hline Variables & \multicolumn{2}{|c|}{ Sex } & \\
\hline Overall mean (age in years) & 37 & 35 & 36 \\
\hline SD & $(28.38-53.62)$ & $(20.97-49.03)$ & $(21.06-50.94)$ \\
\hline
\end{tabular}

Age group (years)

$$
\begin{aligned}
& <10 \\
& 10 \mid-19 \\
& 20 \mid-29 \\
& 30 \mid-39 \\
& \geq 40
\end{aligned}
$$

$\begin{array}{cc}3 & 6.8 \\ 4 & 9.1 \\ 8 & 18.2 \\ 10 & 22.7 \\ 19 & 43.2\end{array}$

Education level

primary education secondary education higher education not applicable or not reported

Main activity in previous 15 days agriculture

domestic

gold mining

plant extractivism

road/dam construction

mining

travelling

other activities

not reported

$\begin{array}{cc}18 & 40.9 \\ 22 & 50.0 \\ 2 & 4.5 \\ 2 & 4.5\end{array}$

$\begin{array}{cc}2 & 2.4 \\ 9 & 11.0 \\ 18 & 22.0 \\ 22 & 26.8 \\ 31 & 37.8\end{array}$$$
40
$$$$
33
$$

48.8

40.2

7.3

3.7

$$
\begin{gathered}
2.3 \\
27.3 \\
4.5 \\
0.0 \\
0.0 \\
2.3 \\
0.0
\end{gathered}
$$$$
\begin{array}{ll}
16 & 36.4 \\
12 & 27.3
\end{array}
$$

Probable location of infection

$$
\begin{aligned}
& \text { locations within Ananindeua municipality } \\
& \text { other locations } \\
& \text { not reported }
\end{aligned}
$$

$\begin{array}{ccc}12 & 9.5 & 18 \\ 34 & 26.9 & 61 \\ 0 & 0.0 & 01\end{array}$

$$
3
$$

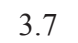

1.2

2.4

1.2

1.2

2.4

2.4

63.4

\section{0}

10.3

20.6

25.4

39.7

$\begin{array}{ll}50 & 39.7\end{array}$

46.0

43.6

6.3

3.9

SD: standard deviation. The number in parentheses is the confidence interval (mean plus and minus 2 standard errors). Source: Sistema de Informação de Vigilância Epidemiológica de Malária (SIVEP/Malária) notification form, July/2014. 


\section{DISCUSSION}

The overall socio-economic impact of malaria is extensive, making this disease a major public health problem in the tropical and subtropical areas of the world ${ }^{(15)}$. Poor socioeconomic and sanitation conditions are factors directly related to maintaining the high prevalence and incidence of parasitic diseases such as malaria ${ }^{(16)}$. In addition, there are numerous health problems resulting from poor education of the population that require corrective and/or educational measures. More informed and literate populations have greater autonomy in self-care and prevention of such diseases ${ }^{(17)}$. Another aspect to be considered is that the lack of water supply may lead to new approaches, such as handmade wells and domestic water tanks, among others. If these alternative systems are not well-sealed, they can serve as breeding sites for malaria vectors, causing a proliferation of said vectors and disease spread $^{(18)}$.

In Pará, an inverse correlation between API and QLI was reported, i.e., the lower the QLI, the greater the risk of contracting malaria in any particular state area ${ }^{(7)}$. Our findings cannot confirm this hypothesis, a limitation we acknowledge. Nevertheless, we believe that the Ananindeua municipality has good basic sanitation and socioeconomic conditions, which presumably may have led to the risk-free classification in almost every year of the study, with API values of less than 1 .

Despite the good basic sanitation and socioeconomic conditions in the Ananindeua municipality, a malaria outbreak occurred in the period from March to May 2013. The lower number of cases in previous years, the decrease in malaria cases between June and December 2013, and the record of only three cases until December $2014^{(6)}$ leads us to believe that the malaria control service is effective, with quick diagnosis and treatment, thus keeping the situation stable in the municipality. It is likely that other factors unrelated to these conditions, such as cases imported from other endemic locations, act as a potential sources of infection. This possibility suggests the need for ad-hoc and thorough surveys in different areas within the municipality where cases have occurred, aiming to provide a better understanding of the outbreak.

Plasmodium vivax is the most prevalent vector species in the State of Pará and was also the most frequently reported parasite in the municipality of Ananindeua, especially in regard to the 2013 outbreak. This prevalence underscores the fact that the dynamics of malaria transmission in Ananindeua are similar to those reported in other areas of the country ${ }^{(6)(19)(20)(21)}$, where this species of Plasmodium is responsible for most detected cases. In addition, the State of Pará has an API $\geq 50$, classifying it as a high-risk area for malaria, due to the high number of reported cases. In 2013, 25,401 cases of malaria were recorded across the state, characterizing the disease as endemic to the $\operatorname{area}^{\left({ }^{(}\right)}$. However, different APIs have been observed in analyses by municipality and/or mesoregions, which in fact show that the distribution of malaria in the state is heterogeneous ${ }^{(6)}(7)(22)$. The municipality of Ananindeua exemplifies this irregularity because, in spite of being in an endemic malaria state, it is itself not an endemic area and, according to the API, was risk-free for the 10-year study period, except 2003 , when it was classified as having a low risk of infection.

With respect to the seasonality of the investigated cases, contradictory results were observed in the first and last years of the study period. During 2003, we detected two peaks, one in January and the other in November. The peak in January may reflect an outbreak in Ananindeua or simply the accumulation of reports from previous years, as these reports were only made available by SIVEP in 2003, the year of its creation $^{(6)}$. In comparison, in 2013, the peak was detected in April and characterized as an outbreak. These fluctuations can be explained by variations in the occurrence of rainfall ${ }^{(23)}$ and the introduction of infected individuals into the municipality.

Malaria behaves like an occupational disease because it reaches people who are part of uncontrolled migration and who occupy rural areas, especially those involved in activities related to the mining of gold and other minerals, agricultural settlements, timber exploitation, and agricultural activities ${ }^{(15)(22)}$. The predominance of cases of adults and males performing activities considered high risk for contracting the disease corroborates other studies in the Amazon region ${ }^{(16)(20)(22)}$. However, the urbanization of malaria occurs due to an increase in migratory flow, because individuals infected while working bring the pathogen to urban areas, where the high population density and the rural habits of populations with lower QLI, living in environmentally fragile environments, favor the spread of malaria ${ }^{(24)}$.

In Ananindeua, the majority of individuals affected by malaria in 2013 were male adults ( $\geq 40$ years) who had completed primary education, a pattern consistent with that observed in other areas of the Brazilian Amazon. In fact, adult males are more susceptible due to their greater displacement in the Amazon region and their involvement in activities in environments conducive to transmission ${ }^{(16)(20)}$. Although a minority (22.2\%) of individuals reported activities in the last 15 days relating to agriculture, gold mining, plant extractivism, $\mathrm{road} /$ dam construction, mining, and traveling, notably, the option other activities was marked on 54\% (68/126) of the forms analyzed, and such information was missing from $23.8 \%$ (30/126) of the forms. Two possible explanations may explain the evidence of imported cases during the outbreak. First, it is possible that bias occurred relating to the non-recognition of displacement of carriers to municipalities near Ananindeua, whether for work or leisure, as travel because only $1.6 \%(2 / 126)$ of affected individuals reported having traveled. However, when we analyzed the question regarding potential infection sites from the 126 forms of the Epidemiological Surveillance Information System/Malaria Case Notification during the year 2013, only $31(24.6 \%)$ individuals mentioned the municipality of Ananindeua as their possible site of contamination. The other possibility may be related to a lack of preparation and/or neglect of health agents in filling out the epidemiological forms. However, we must consider that the occurrence of a malaria outbreak in this case could also be a consequence of the autochthonous transmission of $P$. vivax or relapses (old malaria profile) $)^{(19)(25)}$ and may not necessarily be related to recent introduction of 
the disease to this area. Furthermore, asymptomatic carriers of $P$. vivax could have some epidemiological importance as a source of infection for vectors ${ }^{(16)(19)}$, since they are able to maintain the parasite transmission.

Continuous surveillance activities are required for the Ananindeua municipality to evaluate vulnerability and susceptibility in different locations and to enable rapid diagnosis and treatment throughout the healthcare network. Our results confirm the non-endemicity of malaria in the municipality analyzed, given that it was classified as risk free from 20042013. However, the 2013 outbreak indicates the need to map risk areas and reevaluate vector species with the potential for transmission, considering that the expectation remains that Plasmodium will be reintroduced and that malaria will reemerge in areas now considered controlled.

\section{CONFLICT OF INTEREST}

The authors declare that there is no conflict of interest.

\section{FINANCIAL SUPPORT}

\section{Universidade Federal do Pará and Instituto Evandro} Chagas.

\section{REFERENCES}

1. Pina-Costa A, Brasil P, Di Santi SM, Araujo MP, Suárez-Mutis MC, Santelli ACFS, et al. Malaria in Brazil: what happens outside the Amazonian endemic region. Mem Inst Oswaldo Cruz 2014; 109:618-633.

2. Oliveira-Ferreira J, Lacerda MVG, Brasil P, Ladislau JLB, Tauil PL, Daniel-Ribeiro CT. Malaria in Brazil: an overview. Malar J 2010; 9:115.

3. Lorenzetti A, Fornazari PA, Bonini-Domingos AC, Penhalbel RSR, Fugikaha E, Bonini-Domingos CR, et al. Mixed Plasmodium falciparum infections and its clinical implications in four areas of the Brazilian Amazon region. Acta Trop 2008; 107:8-12.

4. Ministério da Saúde. Secretaria de Vigilância em Saúde. Departamento de Vigilância em Saúde. Boletim Epidemiológico 2013. (Internet). Brasília: Ministério da Saúde; 2013 (Cited 2014 July 01). Available at:http://bvsms.saude.gov.br/bvs/periodicos/ boletim_epidemiologico_numero_1_2013.pdf

5. Ministério da Saúde. Sistema Nacional de Vigilância em Saúde. Relatório de situação: Pará (Internet). Brasília: Ministério da Saúde; 2011 (Cited 2014 July 19). Available at: http://bvsms.saude.gov.br/ bvs/publicacoes/sistema_nacional_vigilancia_saude_pa_5ed.pdf

6. Sistema de Informação de Vigilância Epidemiológica (SIVEP) de Malária (Internet). SIVEP; 2014 (Cited 2014 August 27). Available at: www.saude.gov.br

7. Lima-Junior SG, Pamplona VMS, Corvelo TCO, Ramos EMLS. Quality of life and the risk of contracting malaria by multivariate analysis in the Brazilian Amazon region. Malar J 2014; 13:86.

8. Limongi JE, Chaves KM, De Paula MBC, Costa FC, Silva AA, Lopes IS, et al. Malaria outbreaks in a non-endemic area of Brazil, 2005. Rev Soc Bras Med Trop 2008; 41:232-237.
9. Governo do Estado do Pará. Instituto de Desenvolvimento Econômico, Social e Ambiental do Pará. Estatística Municipal de Ananindeua (Internet); 2013 (Cited 2014 August 29). Available at: www.iah.iec. pa.gov.br/iah/fulltext/georeferenciamento/ananindeua.pdf

10. Instituto Brasileiro de Geografia e Estatística (IBGE). Resultado da amostra do censo demográfico 2010. (Internet). IBGE; 2010 (Cited 2014 August 27). Available at: www.ibge.com.gov.br

11. Rede Interagencial de Informações para a Saúde (RIPSA). IDB2007. Tema do Ano: Nascimentos no Brasil (Internet). 2008 (Cited 2014 September 20). Available at: http://tabnet.datasus.gov.br/cgi/ idb2007/tema.pdf

12. Seu Consultor Financeiro. Inteligência Financeira/ Entenda a Economia/Onde Investir. Noções Financeiras Essenciais. Seu consultor Financeiro. (Internet). (Cited 2014 September 20). Available at: www.seuconsultorfinanceiro.com.br/ inteligenciaFinanceira.php?secao=71\&parametro187

13. Marques AC. Manual de Terapêutica da Malária. Brasília: Fundação Nacional de Saúde; 2001.

14. Ministério da Saúde. Resolução $\mathrm{n}^{\circ} 466$, de 12 de dezembro de 2012 (Internet). Conselho Nacional de Saúde; 2012 (cited 2014 September 20). Available at: bvsms.saude.gov.br/bvs/saudelegis/ cns/2013/res0466_12_12_2012.html

15. Machado RLD, Couto AARA, Cavasini CE, Calvosa VSP. Malária em região extra-Amazônica: situação no Estado de Santa Catarina. Rev Soc Bras Med Trop 2003; 36:581-586.

16. Tada MS, Marques RP, Mesquita E, Dalla Martha RC, Rodrigues JA, Costa JD, et al. Urban malaria in the Brazilian Western Amazon Region I: high prevalence of asymptomatic carriers in an urban riverside district is associated with a high level of clinical malaria. Mem Inst Oswaldo Cruz. 2007; 102:263-269.

17. Ribeiro DF, Correia BR, Soares AKF, Rocha MKL, Alves ERP, Albuquerque MCPA. Educação em saúde: uma ferramenta para a prevenção e controle de parasitoses. Rev Univ Vale do Rio Verde 2014; 11:300-310.

18. Bicudo CEM, Tundisi JG, Scheuenstuhl MCB. Águas do Brasil: análises estratégicas. São Paulo: 2010. Rio de Janeiro: Academia Brasileira de Ciências. Instituto de Botânica; 2010.

19. Barbosa S, Gozze AB, Lima NF, Batista CL, Bastos MS, Nicolete $\mathrm{VC}$, et al. Epidemiology of disappearing Plasmodium vivax malaria: a case study in rural Amazonia. PLoS Negl Trop Dis 2014; 8:e3109.

20. Couto RA, Latorre MRDO, Di Santi SM, Natal D. Malária autóctone notificada no Estado de São Paulo: aspectos clínicos e epidemiológicos de 1980 a 2007. Rev Soc Bras Med Trop 2010; 43:52-58.

21. Parise VE, Araújo CG, Castro DGJ. Aspectos Epidemiológicos da Malária no Estado do Tocantins, Brasil e a Origem dos Casos Período 2003 a 2008. Rev Patol Trop 2012; 41:442-456.

22. Duarte EC, Ramalho WM, Tauil PL, Fontes CJF, Pang L. The changing distribution of malaria in the Brazilian Amazon, 20032004 and 2008-2009. Rev Soc Bras Med Trop 2014; 47:763-769.

23. Braz RM, Guimarães RF, Carvalho Júnior OA, Tauil PL. Spatial dependence of malaria epidemics in municipalities of the Brazilian Amazon. Rev Bras Epidemiol 2014; 17:615-628.

24. Terrazas WCM. Desenvolvimento de SIG para análise epidemiológica da distribuição espacial da malária no município de Manaus - um enfoque em nível local. Rio de Janeiro: Fundação Oswaldo Cruz; 2005.

25. Val FF, Sampaio VS, Cassera MB, Andrade RT, Tauil PL, Monteiro $\mathrm{WM}$, et al. Plasmodium vivax malaria elimination: should innovative ideas from the past be revisited? Mem Inst Oswaldo Cruz 2014; 109:522-524. 